\title{
Análise da qualidade visual da paisagem da região de Tibagi, PR, aplicando o sensoriamento remoto
}

\author{
Geraldo S. Landovsky ${ }^{1}$, Daniela B. Batista ${ }^{2} \&{\text { Hideo } \text { Araki }^{3}}^{3}$ \\ RESUMO
}

A avaliação da qualidade visual de paisagens tem-se mostrado ferramenta eficiente para a determinação de diretrizes de usos adequados do solo, levando-se em conta o potencial atrativo dos diversos tipos de cobertura da superfície terrestre. Dentre os empregos das imagens orbitais, é bastante difundida a geração de mapas de ocupação do solo que podem, por sua vez, servir de base para a avaliação da paisagem. Com o presente trabalho objetivou-se propor e testar uma metodologia para a avaliação da qualidade visual da paisagem, através do emprego de imagem orbital classificada e pós-processada e da implementação de um algoritmo específico, para avaliação dos diversos usos da superfície na área em estudo. Para tanto e com base no método indireto de avaliação da paisagem, desenvolveu-se um algoritmo computacional que se utiliza de imagens orbitais para a valoração paisagística. Os resultados obtidos foram mosaicos e mapas da qualidade visual da paisagem da área de estudo. Ao final, concluiu-se que a técnica de avaliação através do programa computacional mostrou-se adequada à finalidade proposta; no entanto, deve ainda ser tida como resultado prévio e base para estudos mais detalhados.

Palavras-chave: valoração, uso da terra, imagens orbitais

\section{Landscape quality analysis of Tibagi, Paraná state, applying the remote sensing}

\begin{abstract}
The evaluation of landscapes has been showing an efficient tool for purposes of determining the appropriate land uses, considering the potential attraction of the several types of terrestrial surface covering. Among the employments of the orbital images, the generation of land use maps is quite spread, which serves as base for the landscape evaluation. The present work has the objective to propose and to test a methodology for the visual quality evaluation of the landscape, through the employment of classified and post-processed orbital image and implementing a specific algorithm, for evaluation of several uses of the land surface in the study area. Thus, on the basis of indirect method of landscape evaluation, an algorithm that uses of orbital images for the landscape evaluation was developed. The obtained results were mosaics and maps of the visual quality of landscape of the studied area. At the end, it was concluded that the computational program technique evaluation was found to be appropriate for the proposed purpose, however, it should be considered as preliminary result and base for more detailed studies.
\end{abstract}

Key words: valuation, land use, orbital image

${ }^{1}$ Instituto Brasileiro de Geografia e Estatística (IBGE), Gerência de Geodésia e Cartografia da Unidade Estadual do Ceará. Av. 13 de Maio 2881, Benfica, CEP 60040-531, Fortaleza, CE. Fone (85) 34645382 - E-mail: landovsky@ibge.gov.br

2 Departamento de Ciências Florestais/UFPR. Av. Pref. Lothário Meissner 3400, Jardim Botânico, CEP 80210-170, Curitiba, PR. Fone (41) 33603242

- E-mail: dbiondi@floresta.ufpr.br

${ }^{3}$ Departamento de Geomática. Centro Politécnico/UFPR, bloco 6, $1^{\circ}$ andar, Jardim das Américas, CEP 81531-990, Curitiba, PR. Fone (41) 33613638

- E-mail: haraki@geoc.ufpr.br 


\section{INTRODUÇÃO}

Um dos principais usos das imagens de satélite é a geração de mapas temáticos, com maior freqüência os de uso da terra. A aquisição periódica de imagens permite a realização de estudos temporais das tendências de ocupação da terra, porém o que se tem de mais evidente são as regiões que tiveram sua cobertura alterada, seja por exemplo, pelo crescimento em dimensão das áreas agrícolas ou pela mudança no estágio de desenvolvimento da vegetação.

A ciência da paisagem é um ramo relativamente novo da ciência. As primeiras pesquisas que enfocaram paisagem como elemento central datam da década de 1960; desde então, a ciência da paisagem passou a fazer parte dos estudos e projetos em várias áreas de planejamento. Atualmente, o estudo da paisagem está integrado ao planejamento regional em diversos países sendo, inclusive, fator determinante na implantação ou não de um projeto ou obra de engenharia, e seu emprego pode revelar informações intrínsecas ao mapa temático gerado a partir de uma imagem orbital, como o empobrecimento da qualidade visual de uma região, em conseqüência da implantação de uma obra de engenharia ou da ocorrência de um desmatamento; assim, a valoração da paisagem pode ser considerada um recurso que permite avaliar a qualidade visual ou cênica de uma região com rapidez e eficácia, quando aliada às técnicas de sensoriamento remoto podendo, ainda, ser viável econômica e tecnicamente, nas questões de planejamento urbano e regional e de uso racional do solo.

Com relação à atual situação e às necessidades do estudo de paisagens e suas aplicações, Silva et al. (1998), sugerem que se utilize menos estudos descritivos e mais estudos metodológicos e de modelagem. De acordo com Rocha (1995), é evidente a multiplicidade de perspectivas abertas para o emprego de metodologias na análise da paisagem. Para cada situação, deve-se observar os padrões típicos nos quais se apresentam os componentes da paisagem, ou seja, os diferentes arranjos possíveis entre os mosaicos formados pela combinação de formas superficiais do terreno, aspectos bióticos e intensidades diferenciadas de antropização. Atualmente, além dos mapas temáticos em diversas escalas, outras fontes de informação cartográfica são preconizadas para a avaliação da paisagem, entre elas as imagens obtidas por sensores a bordo de satélites, as fotografias aéreas, os sistemas de informações geográficas (SIG), a modelagem e os modelos fractais, estes últimos referentes ao processamento digital de imagens (Rocha, 1995; Porto, 1999).

A paisagem definida por Laurie (1976), é um espaço que, quando visto ou descrito em termos de suas características fisiográficas e ambientais relacionadas com os impactos antropogênicos, é de grande importância nos estudos de planejamento urbano e regional; já Villota (1991) diz que a paisagem é a unidade fundamental e básica para definir os diversos tipos de solo existentes. Pode-se, então, a partir daí, utilizar o estudo da paisagem como subsídio para a definição de usos e ocupação do solo. Forman \& Godron (1986) definem a paisagem como uma superfície geográfica heterogênea, constituída por um grupo de ecossistemas que se repetem apresentando padrões semelhantes.
Pires (1993) diz que, nos últimos vinte e cinco anos, se consagrou, em alguns países, principalmente na Europa e América do Norte, o processo institucional do planejamento da paisagem, cujas etapas técnicas ou científicas passaram a exigir o desenvolvimento de estudos sobre a paisagem, tomada na sua dimensão visual e territorial. Também enfatiza a importância desse estudo, relacionando-o à crescente demanda social pelos valores ambientais através das qualidades cênicas e naturalísticas da paisagem.

Naveh \& Lieberman (1994) afirmam que o planejamento paisagístico deve unir-se ao ecológico, como parte integrante, salientando a necessidade de avaliação quantitativa do impacto total do uso do solo e sua específica e necessária utilidade na paisagem, especialmente em se levando em conta o campo da recreação. A integração da paisagem como variável do meio físico passou a ser uma necessidade urgente a ser tratada e seu estudo e valoração deve ser prévio a qualquer projeto de planejamento de usos do solo (Alvarez-Alfonso, 1990).

Pires (1993) afirma que os estudos da paisagem compreendem desde uma mera descrição até uma tipificação ou classificação em unidades homogêneas e desde estudos de percepção visual até a determinação da qualidade e fragilidade visuais, com uso intenso de técnicas estatísticas. Canteras (1992) diz que os métodos de avaliação da paisagem variam desde aqueles baseados nas considerações estéticas, portanto subjetivos, até os métodos através dos quais se pretende avaliar, objetivamente, a qualidade da paisagem mediante seus componentes. Existem várias classificações dessas metodologias em função dos critérios empregados, ou dos sistemas de medida ou, ainda, da participação de usuários etc.

O Método Indireto das Componentes da Paisagem é aplicado através da análise dos componentes físicos (meio abiótico: água, topografia), dos componentes biológicos (meio biótico: vegetação, fauna) e dos componentes antrópicos (uso do solo). Tais componentes devem ser valorados através de unidades regulares (malha reticulada) ou unidades irregulares (em função de um componente definidor da paisagem, por exemplo). Os métodos de avaliação e/ou valoração da paisagem diferem entre si em vários aspectos, relacionados à sua aplicação, finalidade e resultado. Em termos de objetividade, os métodos ditos indiretos, isto é, aqueles onde a paisagem é avaliada a partir de seus componentes, são os que menos expressam valores subjetivos, sendo por isso mais fácil e amplamente aplicados na avaliação paisagística regional.

O presente trabalho objetivou propor e testar uma metodologia para a avaliação da qualidade visual da paisagem da região de Tibagi, PR, através do emprego de imagem orbital classificada e pós-processada e da implementação de um algoritmo específico, para avaliação dos diversos usos da superfície na área em estudo. Também foi realizada a avaliação pelo método indireto de avaliação da paisagem para fins de comparação.

\section{MATERIAL E MÉTODOS}

\section{Área de estudo}

A área de estudo do presente trabalho localiza-se no município de Tibagi, inserido nos Campos Gerais, localizado 


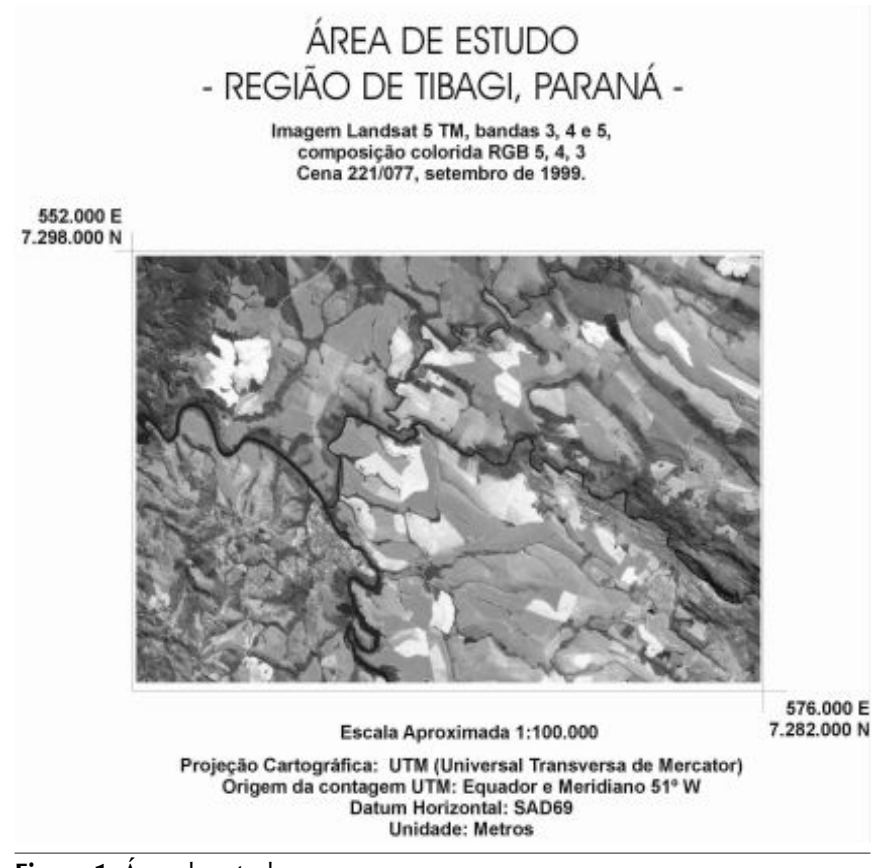

Figura 1. Área de estudo

na região Centro Sul do Estado do Paraná. Tibagi limita-se com os municípios de Telêmaco Borba e Ventania, ao Norte, a Leste com os municípios de Piraí do Sul, Castro e Carambeí, ao Sul com Ponta Grossa e Ipiranga, e a Oeste, com Ivaí, Reserva e Imbaú. A cidade de Tibagi está localizada na margem esquerda do Rio Tibagi, com coordenadas geográficas aproximadas de $24^{\circ} 30^{\prime} 49,5^{\prime \prime}$ de Latitude Sul e $50^{\circ} 24^{\prime} 55^{\prime \prime}$ de Longitude Oeste, situada a $732 \mathrm{~m}$ acima do nível do mar (Maack, 1968). Como área de teste (Figura 1) foi escolhida a região delimitada pelas seguintes coordenadas geográficas: $24^{\circ} 25^{\prime} 49^{\prime \prime} \mathrm{S}, 50^{\circ} 29^{\prime} 13^{\prime \prime} \mathrm{W}$ (canto superior esquerdo) e $24^{\circ} 34^{\prime} 26^{\prime \prime} \mathrm{S}, 50^{\circ} 14^{\prime} 57^{\prime \prime} \mathrm{W}$ (canto inferior direito). Esta área apresenta ampla e representativa quota da diversidade paisagística regional e é mostrada na Figura 1, através da imagem orbital da área de estudo.

\section{Paisagem da área de estudo}

A partir da escala adotada no presente trabalho - uma escala regional, macro - pode-se visualizar os componentes da paisagem da região de estudo através da estrutura apresentada por Forman \& Godron (1986), como sendo a matriz os campos gerais, os corredores os cursos d'água e suas bor- das com vegetação florestal e, como fragmentos ou manchas, os bosques de floresta nativa, os reflorestamentos e os afloramentos rochosos.

Esteticamente, o cenário paisagístico da área de estudo pode ser percebido por suas impressões visuais primárias forma, cor, textura e escala (Canteras, 1992, Biondi, 2000) através da configuração dos usos do solo, da expressão do relevo e da sazonalidade. O uso agrícola das terras provoca um mosaico de padrões de formatos que, aliados à variedade do relevo local e às rotações cíclicas de culturas cultivadas, torna a região altamente atrativa, em termos de cores, formas e texturas. A escala pode ser vista na extensão dos campos cultivados e na imponência de algumas feições geomorfológicas como, por exemplo, o Cânion do Guartelá (localizado na parte centro-leste da Figura 1).

Dentre as impressões secundárias, unidade, força, variedade, ritmo, dominância, contraste e essência local ou genius loci (Silva et al., 1998, Biondi, 2000), pode-se destacar que a força da paisagem está no seu aspecto de amplidão, de horizonte ao longe; há, também, a alternância entre os componentes tendo-se, por vezes, a dominância de um e, logo a seguir, a variedade dos mesmos, num curto espaço geográfico e de tempo (ao se percorrer a região). O contraste também é altamente vislumbrado, desde a variação do relevo, dos usos da terra e até mesmo do ponto de vista fitoecológico, pois a região guarda elementos de diferentes ecossistemas, como o da Mata Atlântica, do Cerrado e da Caatinga. Destaca-se ainda a essência local, que se mantém, hoje, como em décadas passadas, e é expressa nos hábitos e costumes da região, oriundos de diferentes fontes, como de etnias européias, tribos indígenas e, principalmente, do Tropeirismo (ciclo econômico e social do início do século XVIII). A Figura 2 mostra alguns aspectos da paisagem da área de estudo, através de fotos obtidas durante reconhecimento de campo.

\section{Metodologia}

O desenvolvimento do presente estudo teve por base conceitual o trabalho de Griffith (1979), que empregou o método indireto de avaliação da paisagem para análise dos recursos naturais do Parque Nacional da Serra da Canastra. A metodologia aqui proposta trata de uma implementação no uso do método indireto com a utilização de imagens orbitais para a avaliação paisagística.

$\mathrm{Na}$ realização do trabalho utilizou-se o seguinte material: a) Cartas Topográficas, escala 1:50.000 da DSG (Diretoria
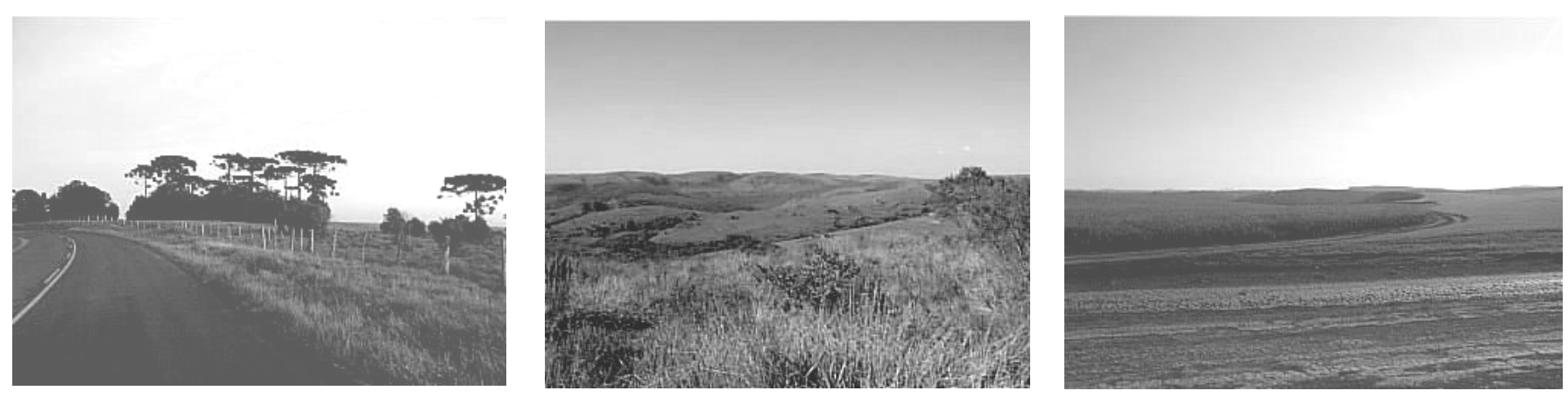

Figura 2. Aspectos da paisagem de Tibagi 
do Serviço Geográfico - Exército do Brasil), Folhas: SG.22-XA-II-3, MI - 2807/3, Rincão da Ponte. Edição 1997; e SG.22-DIV, Castro. Edição 1964; b) Mapa das Florestas, escala 1:100.000 do Mapeamento dos Remanescentes de Floresta com Araucária no Estado do Paraná - PROBIO - MMACNPq. MI's 2807 e 2824. Edição 2001; c) Imagens TM 5 LANDSAT, de setembro de 1999, bandas 3, 4 e 5, cedida pela Empresa Engesat à Universidade Federal do Paraná; d) Os aplicativos: Envi, Multispec e Matlab. Realizaram-se, ainda, levantamento de material bibliográfico pertinente e visitas a campo, para efetivo conhecimento da área de estudo.

O primeiro passo para a aplicação da metodologia proposta foi a aplicação do processo de classificação das imagens TM5 Landsat, composição colorida RGB 5, 4, 3 através da técnica supervisionada e usando a máxima verossimilhança como critério de separabilidade utilizando-se, para isto, o aplicativo Multispec. Levou-se em conta a seguinte ordem para a classificação dos elementos presentes na imagem: água (1), mata nativa (2), reflorestamento (3), agricultura estágio I (4), agricultura estágio II (5), área urbana/rodovias (6), campos/pastagens (7), solo exposto (8), solo com calcário (9), e afloramentos rochosos (10). Esta seqüência foi definida em função da identificação visual das classes e para que se considerasse a mesma ordem na avaliação da qualidade visual da paisagem, porém é uma ordem aleatória, podendo ser alterada, desde que seja considerada em todas as etapas do trabalho. Uma das formas de avaliação da paisagem é a combinação entre as classes (componentes), por exemplo, água e campos/pastagens, respectivamente; neste caso, classes 1 e 7 . Por isso, a adoção da referida sequência.

De posse da imagem classificada, partiu-se para uma segunda fase, quando então foram atribuídos valores individuais de qualidade a cada classe, de acordo com a qualidade visual de cada elemento da paisagem, definidos de forma subjetiva e com base no trabalho de Griffith (1979). A escala empregada para a avaliação da qualidade visual da paisagem compreende valores inteiros iguais a 1, 2, 3, 4 e 5, correspondendo às classes de qualidade visual baixa, média baixa, média, média alta e alta, respectivamente. Desta forma, as classes geradas receberam valores, conforme a Tabela 1 .

O critério utilizado para a atribuição de valores (pesos) para as classes foi o mesmo empregado por Griffth (1979), apenas se adequando as classes existentes na área de estudo, e cuja base é o aspecto visual de cada elemento da paisa-

Tabela 1. Valor individual de cada elemento adotado na valoração da paisagem, através da combinação de elementos

\begin{tabular}{ccc}
\hline Classe & Elemento & Valor Individual \\
\hline 1 & Água & 5 \\
2 & Mata & 5 \\
3 & Reflorestamento & 2 \\
\hline 4 & Agricultura 1 & 3 \\
\hline 5 & Agricultura 2 & 3 \\
6 & Área Urbana/Rodovia & 3 \\
\hline 7 & Campo/Pastagem & 4 \\
\hline 8 & Solo Exposto & 1 \\
\hline 9 & Solo com Calcário & 1 \\
10 & Afloramento Rochoso & 5 \\
\hline
\end{tabular}

gem. Então, foram atribuídos valores às possíveis combinações entre essas classes, seguindo-se a mesma escala de valores, conforme mostrado na Tabela 2 .

Na seqüência, desenvolveu-se um programa em ambiente Matlab, que avalia a paisagem contida na imagem classificada em função dos valores de qualidade visual atribuídos a cada classe e da combinação dessas classes (Tabelas 1 e 2). A elaboração do programa computacional, em linhas gerais, se deu da seguinte maneira: pensando-se na imagem como um grid reticulado, fez-se um algoritmo que lê cada um dos pixels da imagem classificada e, em função da sua

Tabela 2. Valores empregados na avaliação da qualidade visual da paisagem no programa em Matlab

\begin{tabular}{|c|c|c|c|}
\hline $\begin{array}{c}\text { Combinação } \\
\text { (Classe A+ Classe B) }\end{array}$ & Classe $\mathrm{A}$ & Classe B & $\begin{array}{l}\text { Valor } \\
\text { Adotado }\end{array}$ \\
\hline $1+2$ ou 2 + 1 & Água & Mata & 5 \\
\hline $1+3$ ou $3+1$ & Água & Reflorestamento & 4 \\
\hline $1+4$ ou $4+1$ & Água & Agricultura 1 & 3 \\
\hline $1+5$ ou $5+1$ & Água & Agricultura 2 & 3 \\
\hline $1+6$ ou $6+1$ & Água & Área Urbana/Rodovia & 3 \\
\hline $1+7$ ou $7+1$ & Água & Campo/Pastagem & 4 \\
\hline $1+8$ ou $8+1$ & Água & Solo Exposto & 1 \\
\hline $1+9$ ou $9+1$ & Água & Solo com Calcário & 1 \\
\hline $1+10$ ou $10+1$ & Água & Afloramento Rochoso & 5 \\
\hline $2+3$ ou $3+2$ & Mata & Reflorestamento & 4 \\
\hline $2+4$ ou $4+2$ & Mata & Agricultura 1 & 3 \\
\hline $2+5$ ou $5+2$ & Mata & Agricultura 2 & 3 \\
\hline $2+6$ ou $6+2$ & Mata & Área Urbana/Rodovia & 3 \\
\hline $2+7$ ou $7+2$ & Mata & Campo/Pastagem & 4 \\
\hline $2+8$ ou $8+2$ & Mata & Solo Exposto & 2 \\
\hline $2+9$ ou $9+2$ & Mata & Solo com Calcário & 2 \\
\hline $2+10$ ou $10+2$ & Mata & Afloramento Rochoso & 5 \\
\hline $3+4$ ou $3+2$ & Reflorestamento & Agricultura 1 & 3 \\
\hline $3+5$ ou $5+3$ & Reflorestamento & Agricultura 2 & 3 \\
\hline $3+6$ ou $6+3$ & Reflorestamento & Área Urbana/Rodovia & 2 \\
\hline $3+7$ ou $7+3$ & Reflorestamento & Campo/Pastagem & 3 \\
\hline $3+8$ ou $8+3$ & Reflorestamento & Solo Exposto & 1 \\
\hline $3+9$ ou $9+3$ & Reflorestamento & Solo com Calcário & 1 \\
\hline $3+10$ ou $10+3$ & Reflorestamento & Afloramento Rochoso & 3 \\
\hline $4+5$ ou $5+4$ & Agricultura 1 & Agricultura 2 & 3 \\
\hline $4+6$ ou $6+4$ & Agricultura 1 & Área Urbana/Rodovia & 3 \\
\hline $4+7$ ou $7+4$ & Agricultura 1 & Campo/Pastagem & 3 \\
\hline $4+8$ ou $8+4$ & Agricultura 1 & Solo Exposto & 3 \\
\hline $4+9$ ou $9+4$ & Agricultura 1 & Solo com Calcário & 3 \\
\hline $4+10$ ou $10+4$ & Agricultura 1 & Afloramento Rochoso & 4 \\
\hline $5+6$ ou $6+5$ & Agricultura 2 & Área Urbana/Rodovia & 3 \\
\hline $5+7$ ou $7+5$ & Agricultura 2 & Campo/Pastagem & 3 \\
\hline $5+8$ ou $8+5$ & Agricultura 2 & Solo Exposto & 3 \\
\hline $5+9$ ou $9+5$ & Agricultura 2 & Solo com Calcário & 3 \\
\hline $5+10$ ou $10+5$ & Agricultura 2 & Afloramento Rochoso & 4 \\
\hline $6+7$ ou $7+6$ & Área Urbana/Rodovia & Campo/Pastagem & 3 \\
\hline $6+8$ ou $8+6$ & Área Urbana/Rodovia & Solo Exposto & 1 \\
\hline $6+9$ ou $9+6$ & Área Urbana/Rodovia & Solo com Calcário & 1 \\
\hline $6+10$ ou $10+6$ & Área Urbana/Rodovia & Afloramento Rochoso & 3 \\
\hline $7+8$ ou $8+7$ & Campo/Pastagem & Solo Exposto & 2 \\
\hline $7+9$ ou $9+7$ & Campo/Pastagem & Solo com Calcário & 2 \\
\hline $7+10$ ou $10+7$ & Campo/Pastagem & Afloramento Rochoso & 5 \\
\hline $8+9$ ou $9+8$ & Solo Exposto & Solo com Calcário & 1 \\
\hline $8+10$ ou $10+8$ & Solo Exposto & Afloramento Rochoso & 2 \\
\hline $9+10$ ou $10+9$ & Solo com Calcário & Afloramento Rochoso & 2 \\
\hline
\end{tabular}


classe, atribui ao pixel um valor numérico de qualidade, estabelecido com base nos conhecimentos empregados no estudo da paisagem. Para tanto, o algoritmo busca avaliar a paisagem em termos da combinação dos seus elementos (no caso, das classes) tendo, basicamente, as seguintes etapas: leitura da imagem classificada; contagem e armazenamento do nível de cinza de cada pixel, dentro da quadrícula estabelecida. Esta quadrícula é a unidade utilizada para a avaliação da paisagem. Foram empregadas quadrículas com áreas de aproximadamente $4 \mathrm{~km}^{2}$ (para efeito de comparação com a técnica tradicional também empregada), que equivalem às dimensões de 67 por 67 pixels, totalizando 4489 pixels; uso do critério de avaliação da paisagem: combinação de elementos e geração da visualização gráfica (mosaico) que retrata a qualidade visual da paisagem.

O critério da combinação de elementos da paisagem leva em conta os aspectos visuais de cada classe e suas composições com as demais. No programa, a avaliação é feita da seguinte forma: dentro de cada quadrícula contam-se que classes ocorrem; dessas classes, separam-se as duas de maior freqüência; em seguida, dá-se uma nota à quadrícula, em função do valor que a combinação dessas classes representa, conforme a Tabela 2; caso a quadrícula tenha uma classe majoritária cuja área ocupa mais de $85 \%$ de sua área, ela recebe apenas o valor individual desta classe, mostrado na Tabela 1; o contrário, ou seja, caso a maior classe tenha até $15 \%$ da área, a quadrícula recebe um valor diferencial (zero), pois denota uma grande fragmentação da paisagem.

De posse do mosaico resultante (visualização gráfica do resultado do programa), partiu-se para a análise e interpretação das linhas que configuram a paisagem (rios, vias, capões de mata etc), com a finalidade de delimitar, através de tais linhas, as classes de qualidade visual da paisagem representadas até então por quadrículas. Em outras palavras, esta fase foi a de refinamento do mosaico para a geração do mapa de qualidade visual da paisagem da área de estudo.

Para efeito comparativo, também foi realizada a avaliação pelo Método Indireto, através dos Componentes da Paisagem - metodologia tradicional, empregada por Griffth (1979). Nas cartas topográficas (escala 1:50.000) avaliaram-se as estradas e rodovias, o relevo e a hidrografia e, no mapa de vegetação (escala 1:100.000), a cobertura vegetal e a hidrografia. A imagem de satélite (Figura 1) permitiu uma avaliação geral e atualizada dos usos do solo. A análise foi feita através de uma grade reticulada, pelo estudo da variedade paisagística presente em cada retículo, ou seja, pela presença e quantificação de cada elemento da paisagem em cada quadrícula. A grade de avaliação empregada possui dimensões de 12 colunas por 8 linhas, com 96 quadrículas de aproximadamente $4 \mathrm{~km}^{2}$ cada uma. Os valores adotados para esta avaliação foram de 1 a 5, segundo os contextos analisados (topografia, hidrografia, vegetação e geomorfologia e intervenção antrópica). A referida avaliação também gerou um mosaico, que foi depois intrepretado e, através do traçado das principais linhas de configuração da paisagem (rios, estradas etc.), transformado em um mapa de qualidade visual da paisagem.

\section{RESULTADOS E DISCUSSÃO}

O mosaico mostrado na Figura 3, proveniente da rotina computacional Matlab e, conseqüentemente, o mapa de qualidade visual da paisagem advindo do mesmo (Figura 4), apresentaram quatro das cinco classes de qualidade visual estabelecidas. Dessas cinco classes, ocorreu predominância da classe média de qualidade visual, originada das grandes áreas agrícolas e de campos e pastagens. As duas áreas de alta qualidade visual são composições de classes de vegetação nativa, água e afloramentos rochosos. As regiões de qualidade média alta resultam das mesmas combinações que originaram as áreas de alta qualidade, mas, com participação de classes de agricultura e de campos e pastagem; já as regiões de menor qualidade, ou seja, as de qualidade visual média baixa, foram devidas às combinações e classes de menores valores, como solo exposto e sua ocorrência junto às áreas agrícolas e campos.

O mosaico resultante da aplicação do método indireto de avaliação (Figura 4), por conter um número maior de informações de cada quadrícula, mostra as cinco classes de qualidade visual de paisagem estabelecidas. Neste caso, as áreas de qualidade visual se devem ao somatório do valor das características de cada quadrícula em cada fonte de avaliação (mapa de vegetação, cartas topográficas e imagem). Logo, é evidente que a avaliação ocorreu de maneira mais detalhada, revelando um resultado mais diversificado.

Neste mosaico observa-se que as áreas de baixa qualidade visual ocorrem em locais onde existem principalmente solo exposto e agricultura extensiva. Da mesma forma, as classes de qualidade média baixa, com o acréscimo de valor qualitativo devido à presença de água e vegetação nativa; já as áreas de qualidade mediana se devem às áreas agrícolas e de área urbana e rodovias. A qualidade visual média alta é representada pelas áreas onde o relevo é mais acentuado, isto é, nas proximidades do Cânyon do Guartelá e na região Sudoeste da área de estudo, onde ocorrem serras e morros isolados. Também, a

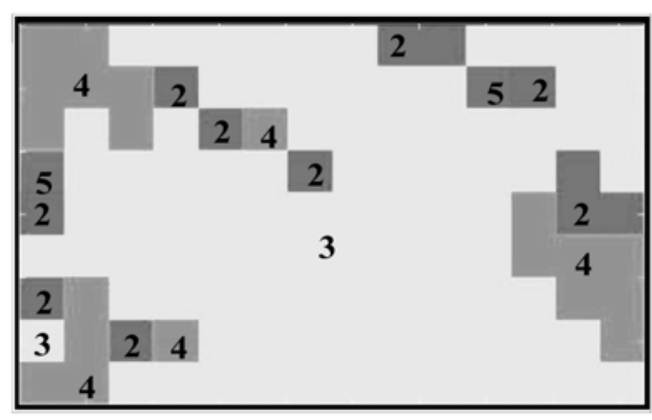

Legenda: Classes de Qualidade Visual

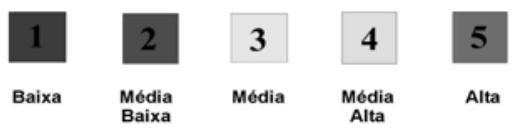

Figura 3. Mosaico advindo do programa em Matlab 


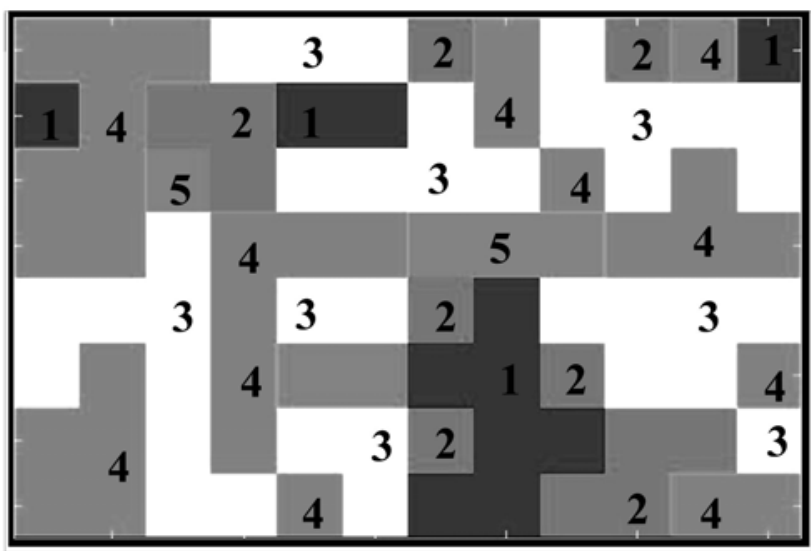

Legenda: Classes de Qualidade Visual

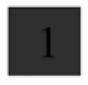

Baixa

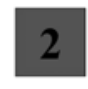

Média

Baixa

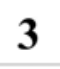

Média

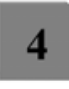

Média

Alta

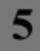

Alta
Figura 4. Mosaico advindo do método tradiconal

vegetação de porte maior e a presença de corpos d'água foram responsáveis pela qualidade visual média alta. Por último, as áreas de alta qualidade visual foram advindas principalmente da existência de rios, vegetação natural e alguns elementos pontuais, como afloramentos de rochas e intervenções antrópicas, no caso, pontes que permitem uma bela vista do seu entorno e, com isso, contribuem para alta na qualidade visual.

Os mapas de qualidade visual da paisagem (Figuras 5 e 6),

\section{MAPA DE QUALIDADE VISUAL DA PAISAGEM}

\section{- REGIÃO DE TIBAGI, PARANÁ -} Baseado no resultado obtido pelo programa em Matlab
através do critério da Combinação de Elementos da Paisagem

\section{$552.000 \mathrm{E}$}

$7.298 .000 \mathrm{~N}$
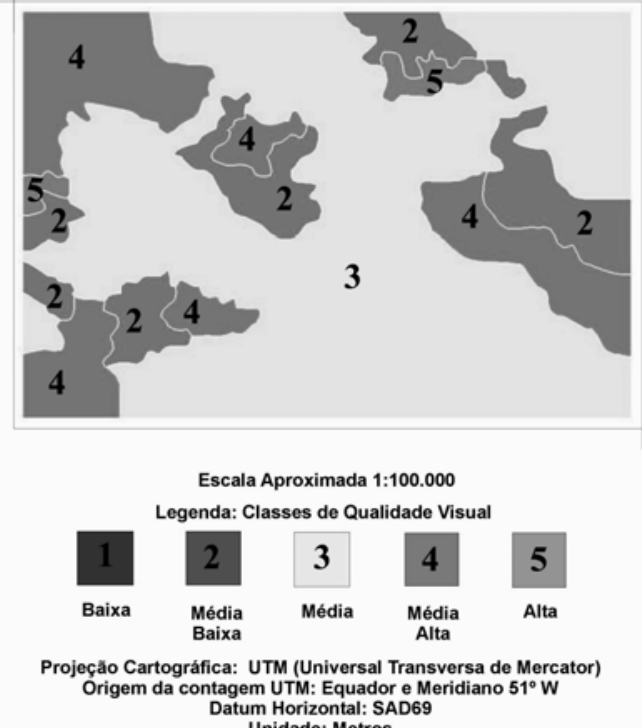

$576.000 \mathrm{E}$

Figura 5. Mapa de qualidade visual da paisagem obtido pelo programa em Matlab produzidos a partir da interpretação dos mosaicos resultantes do programa e da avaliação indireta, mostram os detalhes dos limites físicos das área de cada classe de qualidade visual, nos quais se tentou delinear as linhas que configuram a paisagem local, de maneira a localizar e delimitar as regiões com uma ou outra qualidade visual. Verdade é que, apesar de se trabalhar com valores e critérios definidos e, portanto, com objetividade, a interpretação e representação do mapa de qualidade visual têm muito de subjetividade, uma vez que dependem do avaliador para traçar os limites físicos da qualidade representada por cada quadrícula.

Esses mapas buscam mostrar as áreas de maior e menor apelo paisagístico, de maneira a tentar ser um instrumento para a intervenção dos agentes responsáveis pelo planejamento e desenvolvimento da região. Podem ser destacadas como áreas que merecem ter maiores critérios para sua utilização: as regiões dos cânions dos rios Iapó e Fortaleza, as margens do rio Tibagi e a região Sudoeste, nas proximidades do Morro do Jacaré, que têm forte apelo cênico e podem (e devem) ser mais empregadas para a apreciação de suas paisagens; já as regiões com qualidade visual menos expressiva, que compreendem as áreas agrícolas extensivas e de desmatamento e solo exposto, por mais sazonais que sejam, podem ter suas utilizações planejadas, de modo a não denegrirem a paisagem regional por mais tempo que o necessário.

Os resultados obtidos pelas duas técnicas de avaliação da paisagem empregadas, apresentam características próprias e algumas semelhanças, porém são suas discrepâncias que mais chamaram a atenção, dois resultados diferentes que se devem às formas empregadas na obtenção de cada um. No programa são analisadas todas as classes que ocorrem em

\section{MAPA DE QUALIDADE VISUAL DA PAISAGEM} - REGIÃO DE TIBAGI, PARANÁ -

Baseado no resultado obtido pelo Método Indireto de Valoraçăo da Paisagem, com 5 classes

$552.000 \mathrm{E}$
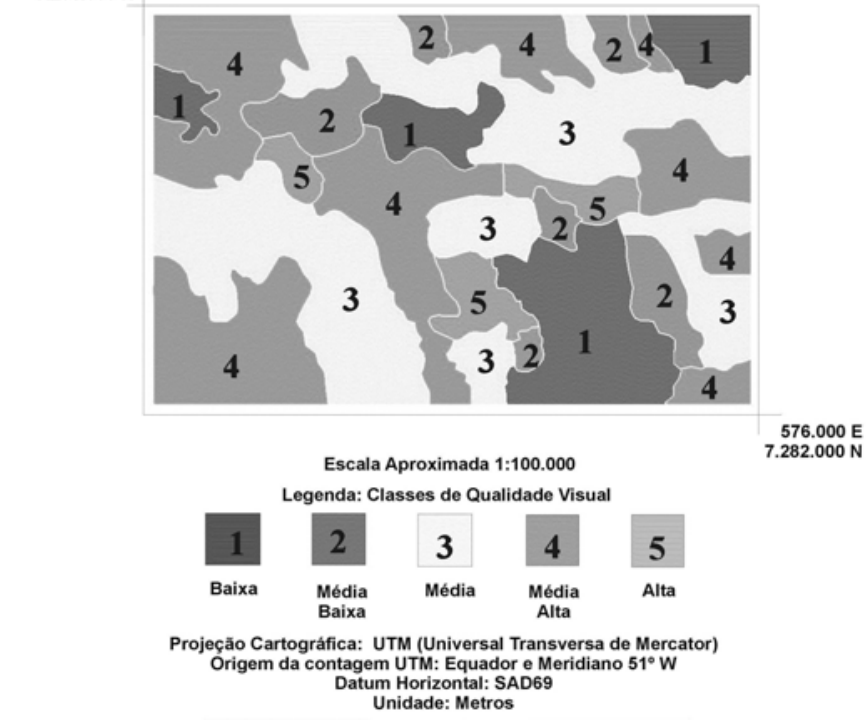
$576.000 \mathrm{E}$
$7.282 .000 \mathrm{~N}$

Figura 6. Mapa de qualidade visual obtido pelo Método Indireto 
cada quadrícula, mas cada região (cada pixel) da quadrícula pertence necessariamente a apenas uma classe, o que não ocorre na forma tradicional de aplicação do método de avaliação, visto que cada região da quadrícula recebe um valor, em função de cada fonte de informação analisada (mapa de vegetação, carta topográfica, imagem) havendo, assim, uma sobreposição de valores. Esse detalhamento promovido pelo método indireto de avaliação da paisagem promoveu resultado que não foi alcançado pela metodologia proposta, uma vez que o resultado desta última descreveu a paisagem da região avaliada de uma maneira bem mais simplificada (vide Figuras 5 e 6). Assim, pode dizer que a metodologia empregada por Griffith (1979) mostrou-se mais efeciente e adequada em realção à metodologia proposta nesse trabalho.

O mapa de qualidade visual da paisagem da região de estudo da Figura 7 mostra tomadas fotográficas de algumas das áreas de cada classe de qualidade visual, com o intuito de ilustrar a paisagem da região; nele, percebe-se que, mesmo as áreas consideradas de baixa qualidade visual, têm um apelo paisagístico, pois são áreas que caracterizam a principal atividade econômica da região: a agricultura; já as áreas de alta qualidade visual podem e devem ser tratadas como de grande importância natural e cultural e, ainda, prioritárias, tanto no seu desenvolvimento e planejamento como na sua proteção, pois são muito ricas em termos paisagísticos.

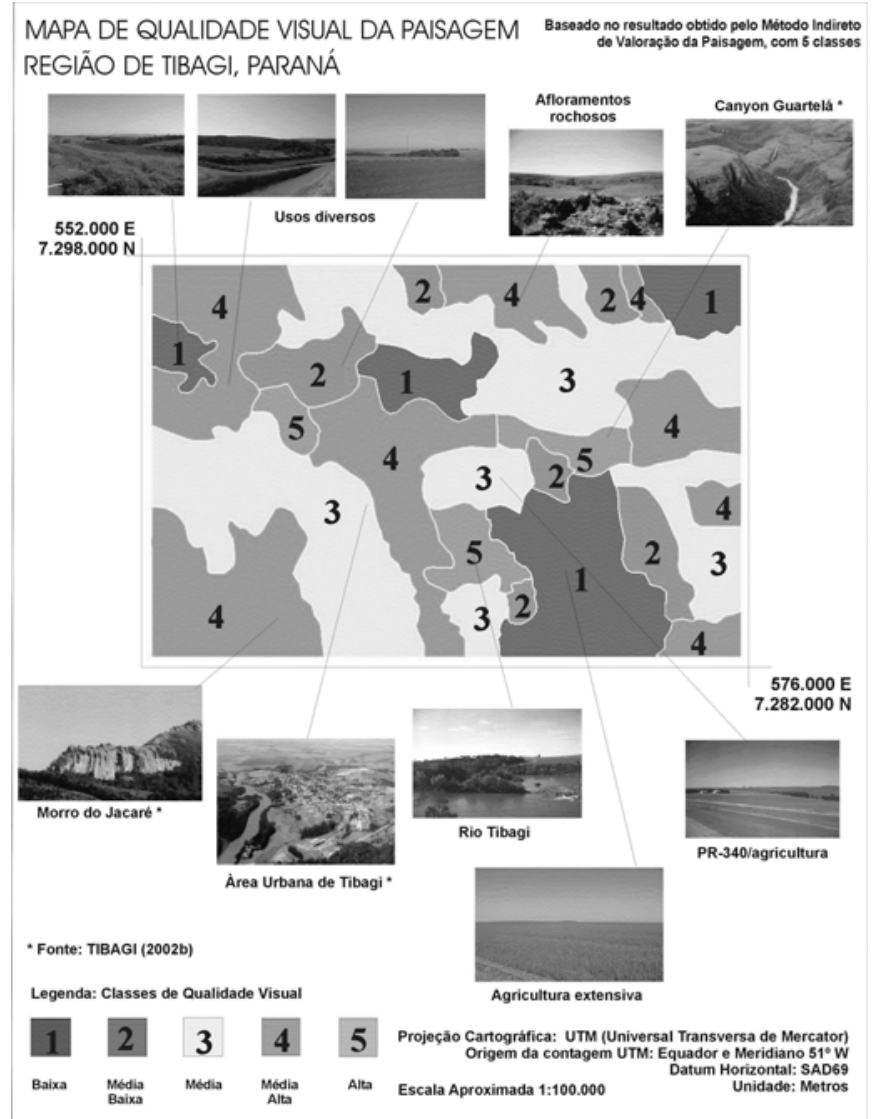

Figura 7. Pontos de interesse paisagístico da área de estudo
De maneira geral, a região de Tibagi pode ser considerada de acentuada atratividade paisagística, principalmente, do ponto de vista de sua diversidade. Os atrativos pontuais mais significativos são entes do relevo e da hidrografia, mas o que caracteriza a paisagem da região são as áreas agrícolas, de campos e pastagens naturais. Os aspectos negativos estão relacionados à intervenção antrópica, sobretudo, nas áreas de agricultura de vasta extensão territorial e de reflorestamentos.

\section{Recomendações}

Ante os resultados obtidos sugere-se que, em trabalhos futuros, os itens seguintes sejam analisados:

1. Deve-se proceder ao teste de outros métodos de classificação que não o da máxima verossimilhança, a fim de se estabelecer o mais adequado.

2. A avaliação da paisagem pelo método indireto tradicional deve incluir a análise de outros temas, como solo, geologia, clima etc, além de maiores detalhes sobre as atividades antrópicas.

3. Na implementação de algoritmos para avaliação da paisagem, há que se verificar novos critérios e valores para cada item analisado.

4. A avaliação da paisagem da região de Tibagi por outras metodologias deve ser procedida com vistas à verificação e/ou confirmação dos resultados obtidos neste estudo.

5. Por último, a metodologia empregada neste trabalho deve ser testada em outras áreas, a fim de se verificar sua eficácia em regiões de paisagem diferentes, como no litoral ou em regiões montanhosas.

\section{CONCLUSÕES}

1. A metodologia tradicional de avaliação (pelo Método Indireto através da técnica dos Componentes da Paisagem) mostrou ser mais eficiente, gerando um mapa de qualidade de paisagem que permite a extração de maior quantidade de informações e detalhes e, consequentemente, tem maior aplicabilidade nas questões referentes ao planejamento regional da área em estudo.

2. De modo geral, os mapas de qualidade visual retrataram a paisagem de forma real, segundo o resultado (mosaico) obtido com cada uma das metodologias empregadas.

3. A técnica de avaliação através do programa em ambiente Matlab mostrou-se adequada à finalidade proposta; no entanto, deve ainda ser tida como resultado prévio, ou seja, pode ser empregada em conjunto com a metodologia tradicional para complementar o trabalho de valoração, visandose o detalhamento.

4. Para regiões onde não se dispõe de material cartográfico para a aplicação do método indireto, a rotina computacional desenvolvida pode tornar-se, aliada às demais técnicas do Estudo da Paisagem e às implementações nos seus critérios de valoração, um ponto de partida para a avaliação de paisagens. 


\section{AGRADECIMENTOS}

Os autores agradecem às Secretarias Municipais de Meio Ambiente e Turismo, e de Educação e Cultura de Tibagi, PR; ao Instituto Brasileiro de Geografia e Estatística (IBGE); à Secretaria Estadual de Meio Ambiente do Paraná (SEMA); ao Instituto Ambiental do Paraná (IAP); à Universidade Federal do Paraná (UFPR); à Minerais do Paraná S.A (MINEROPAR.); à Arquiteta Carmem Leal e à Eng. Cartógrafa Andrea Tedesco.

\section{LITERATURA CITADA}

Alvarez-Alfonso, R. M. Estúdio y valoración del pasaje: territorio de Valderejo. Santander: Universidad de Cantábria, 1990, 136p. Biondi, D. Fundamentos da paisagem no tratamento ambiental de rodovias. In: Simpósio Nacional de Recuperação de Áreas Degradadas "Silvicultura Ambiental", 4,2000. Anais... Blumenau: 2000, CD Rom.

Canteras, J. C. Introducción al paisaje. Curitiba: UFPR e Universidad de Cantabria, 1992, 60p.

Forman, R. T. T.; Godron, M. Landscape ecology. New York: John Wiley \& Sons, 1986, 619p.
Griffith, J. J. Análise dos recursos visuais do parque da Serra da Canastra. Brasil Florestal. Viçosa, n.40, p.13-21, 1979.

Laurie, M. Introducción a la arquitectura del paisaje. Barcelona: Editorial Gustavo Gili S.A, 1976, 213p.

Maack, R. Geografia física do Paraná. Curitiba: UFPR, 1968, 350p.

Naveh,Z:; Lieberman, A. S. Landscape ecology: theory and application. New York: Springer-Verlag, 1994,360p.

Pires, P. S. Avaliação da qualidade visual da paisagem na região carbonífera de Criciúma, SC. Curitiba: UFPR, 1993, 76p. Dissertação Mestrado

Porto, M. L. Ecologia da paisagem. Porto Alegre: UFRG, 1999, CD Rom.

Rocha, C.H. Ecologia da paisagem emanejo sustentável em bacias hidrográficas: Estudo do Rio São Jorge nos Campos Gerais do Paraná. Curitiba: UFPR, 1995, 176p. Dissertação Mestrado

Silva, E:; Zampieri, S. L.; Loch, C. Paisagem: regressão e prognose como elementos para avaliação da ocupação e mudanças do espaço rural. Universidade Federal de Santa Catarina, 1998. http://www.cartografia.org.Br/xixcbcc/artigos/c5/ cv-10/cv10-99a.pdf20 Out.2001.

Villota, H. Geomorfologia aplicada a levantamientos edafológicos y zonificación física de las tierras. Bogotá: Instituto Geográfico Agustín Codazzi, 1991, 211p. 